\title{
A Segunda Guerra Mundial e as políticas econômicas no Brasil
}

\section{The Second World War and the economic policies in Brazil}

\author{
Marcos Dalcastagne $^{1}$
}

Resumo: O presente artigo é um estudo da conjuntura da economia brasileira durante os anos que o país esteve diretamente envolvido na Segunda Guerra Mundial (1942 - 1945). Percebe, no período, intensa produção do medo da escassez que afligiu a população; a campanha governamental de mobilização do trabalho, e as relações com o setor empresarial. Trata, sobretudo, de um esforço por compreender como variados seguimentos da população foram alvo desta campanha de mobilização que visava um violento enquadramento segundo os ideais de ordem do período conhecido como Estado Novo (19371945).

Palavras-chave: Estado Novo, Economia de guerra, Autoritarismo, Escassez e Mobilização, Segunda Guerra Mundial.
Abstract: This article is a study of the situation of the Brazilian economy during the years that the country was directly involved in World War II (1942 - 1945). It was noticed that among the population of the time, there was a great deal of concern that resources would be scarce; a government campaign of work mobilization, and relations with the enterprise sector. Above all, it deals with an effort to understand the various sectors of the population which were a target of the mobilization campaign that had as their aim a violent framing following the ideals of the order known as Estado Novo (1937-1945).

Keywords: Estado Novo, War Economy, Authoritarianism, Shortages and Mobilization, World War II.

A Segunda Guerra Mundial é um dos temas mais recorrentes na historiografia, em livros memorialísticos, no cinema, no jornalismo, em publicações impressas e na imaginação das pessoas. Este evento, cujo palco principal foi em solo Europeu e no Oceano Pacífico, teve a duração oficial

\footnotetext{
${ }^{1}$ Licenciado e Bacharel em História pela Universidade Federal de Santa Catarina, Mestrando de História, Programa de Pós-Graduação em História na Universidade do Estado de Santa Catarina - UDESC. E-mail: dalcastagne@ hotmail.com
} 
de aproximadamente cinco anos (1939 a 1945); mas setenta anos depois de seu final, continua sendo lembrado, ressignificado, e também esquecido, dependendo de quem e o quê fala-se sobre ele.

Este artigo empreende um estudo sobre o aspecto econômico durante os anos em que o Brasil esteve envolvido no conflito mundial (1942 - 1945), observando racionamentos, a escassez de produtos, a intervenção nos sindicatos e as negociações com as classes empresariais. Durante este período, a economia brasileira foi marcada pela produção do medo da escassez e de intensa mobilização do trabalho, realizada principalmente através da propaganda estatal maciça.

Temas como a industrialização, o desenvolvimento econômico e, sobretudo, o projeto nacional, são retomados constantemente nos debates das Ciências Sociais. Estudos sobre as políticas do Estado Novo (1937 1945), e particularmente nos anos de guerra, recebem novos enfoques, abordando mais especificamente a violência na vida política brasileira.

O período no qual o Brasil esteve diretamente envolvido no conflito é o mesmo do auge da intervenção do regime do Estado Novo na vida cotidiana das populações. O que se viu desde a emergência deste regime, em novembro de 1937, foi o recrudescimento do autoritarismo, sobre a égide de um novo projeto de Nação "una, indivisa e coesa". ${ }^{2}$ Política esta que se deu através de ações centralizadoras, como da extinção dos partidos políticos e o intenso controle sobre os sindicatos, o que representava um estado de exceção. ${ }^{3}$ A partir do mês de agosto de 1942, quando o Brasil oficializa a declaração de guerra e a consequente entrada no conflito (posição oficializada quando da declaração de guerra às forças do Eixo, em 31 de agosto daquele ano $^{4}$ ), a intervenção que emergia desde os primeiros anos do Estado Novo se intensifica, tomando ares de cruzada contra os traidores da pátria.

Estes temas são amplamente trabalhados por Boris Fausto, no capítulo $O$ Estado Novo no contexto internacional, do livro organizado por

\footnotetext{
${ }^{2}$ DUTRA, Eliana Freitas. O ardil totalitário. Imaginário político no Brasil dos anos 30. Rio de janeiro : Ed. UFRJ/Ed. UFMG, 1997. p. 33.

${ }^{3}$ Estado de exceção entendido como tendo estreita ligação a guerra civil, uma resposta dos Estados á conflitos que ameacem a ordem. Cf. AGAMBEN, Giorgio. Estado de exceção. São Paulo: Boitempo, 2004. p. 12 - 13.

${ }^{4}$ De acordo com o Decreto Federal $n^{\circ} 10.358$ de 31 ago. 1942 era declarado Estado de Guerra em todo o território nacional. O rompimento de relações diplomáticas com os países do Eixo já datava de 29 jan. 1942. In: MACEDO, Janaina Santos de. Os silenciamentos impostos aos descendentes de alemães em Florianópolis durante o Estado Novo. In: II Jornada Nacional de História do Trabalho durante o X Encontro Estadual de História, 2004, Florianópolis. Anais do X Encontro Estadual de História. Florianópolis: UFSC, 2004. p. 3.
} 
Dulce Pandolfi, Repensando o Estado Novo, ${ }^{5}$ onde os autores lançam novos olhares sobre o regime no contexto internacional; nacional; e especialmente sobre os temas de relevância na política trabalhista de Getúlio Vargas, uma das mais importantes heranças deste período.

Outras pesquisas sobre o Integralismo, ${ }^{6}$ os campos de concentração e os prisioneiros de guerra no Brasil, ${ }^{7}$ tem recebido atenção dos historiadores. Os acontecimentos advindos do estado de guerra alteraram o cotidiano de pessoas, famílias e empresas, cujos reflexos foram estudados pela historiadora Marlene de Fáveri. A autora observa como a polícia política impunha o controle, através da produção do medo de uma possível invasão da Alemanha no sul do Brasil, incidindo sobre as condutas das pessoas, especialmente as que residiam no litoral e nas fronteiras, particularmente no Estado de Santa Catarina. ${ }^{8}$ A historiadora Sandra Guedes percebe, em Joinville, como as leis e decretos que incidiram sobre o cotidiano das populações geraram apreensão e medo, e fizeram produzir táticas que os sujeitos utilizavam frente aos acontecimentos. ${ }^{9}$

Ângela de Castro Gomes, no livro A invenção do trabalhismo, ${ }^{10} \mathrm{e}$ Roney Cytrynowicz, em Guerra sem guerra: a mobilização e o cotidiano em São Paulo durante a Segunda Guerra Mundial, ${ }^{11}$ contribuem no entendimento das relações de poder que ocorreram no campo político na Era Vargas, apresentando ricas análises que enriquecem reflexões no campo do Tempo Presente.

A historiadora Ângela de Castro Gomes identifica o ano de 1942 como um marco cronológico de virada para o Estado Novo. Na conjuntura internacional, com a realização da Conferência do Rio de Janeiro - "III Reunião de Consulta dos Ministros das Relações Exteriores das Repúblicas

\footnotetext{
${ }^{5}$ FAUSTO, Boris. O Estado Novo no contexto internacional. In: Dulce Pandolfi. (Org.). Repensando o Estado Novo. 1ed. Rio de Janeiro: Editora da Fundação Getúlio Vargas, 1999, v. 1. p. 123.

6 BERTONHA, João Fábio. Integralismo: problemas, perspectivas e questões historiográficas. Maringá, PR: EDUEM, 2014.

${ }^{7}$ PERAZZO, Priscila Ferreira. Prisioneiros de Guerra: os súditos do eixo nos campos de concentração brasileiros (1942-1945). São Paulo: Humanitas, Imprensa Oficial, Fapesp, 2009.

${ }^{8}$ FÁVERI, Marlene de. Memórias de uma (outra) guerra: cotidiano e medo durante a segunda guerra em Santa Catarina. 2. ed. Itajaí, SC: Ed. UNIVALI; Florianópolis: Ed. da UFSC, 2005.

${ }^{9}$ GUEDES, Sandra Paschoal Leite de Camargo; OLIVEIRA NETO, Wilson de; OLSKA, Marilia Gervasi. O exército e a cidade. Joinville, SC: Univille, 2008. p. 89 - 97.

${ }^{10}$ GOMES, Ângela de Castro Gomes. A invenção do trabalhismo. RJ: Vértice, 1988.

${ }^{11}$ CYTRYNOWICZ, Roney. Guerra sem guerra: a mobilização e o cotidiano em são Paulo durante a Segunda Guerra mundial. São Paulo: EDUSP, Geração Editorial, 2000.
} 
Americanas" em janeiro do referido ano. Marca-se o fim da possibilidade de uma política eqüidistante do Brasil para com os países envolvidos no conflito, devido a tomada de posição do país em favor dos Estados Unidos. O último dia da conferência marca a decisão presidencial do rompimento diplomático com os países do Eixo, ${ }^{12}$ e a aproximação definitiva do regime Vargas para com os estadunidenses.

Esta ampla negociação, entre os governos do Brasil e dos Estados Unidos para a adesão ao bloco aliado, num contexto de autonomia brasileira graças ao estado de guerra, envolvia barganhas; dentre estas, recursos a fim de (re)equipar o exército brasileiro, e a instalação da Usina Siderúrgica Nacional de Volta Redonda (RJ), marco para a industrialização do país, que tem sua construção iniciada durante aquele período com recursos obtidos do Banco de Exportação e Importação do governo estadunidense (Eximbank). ${ }^{13}$ Por outro lado, houve a concessão para os Estados Unidos de instalar bases militares estratégicas no Nordeste brasileiro, um importante "trampolim" para o esforço de guerra no norte da África. ${ }^{14}$ Este alinhamento atingiu também as relações comerciais, forçando o fim das transações com os países do Eixo.

Esta negociação, porém, foi marcada por idas e vindas, desconfianças mutuas e embates, ficando dado que a adesão do Brasil ao lado estadunidense tinha um preço a ser pago. ${ }^{15}$ Até mesmo por que o fim das relações com a Alemanha representava um forte golpe nas exportações e importações brasileiras, até então um dos maiores parceiros comerciais do Brasil. Segundo Maria Luiza Renaux Hering, nos anos anteriores a guerra, as exportações brasileiras eram: 30,1\% dos EUA/ 19,2\% da Inglaterra/ e 9\% da Alemanha. Já um ano antes do começo do conflito, em 1938, este cenário havia se equilibrado para: $24,2 \%$ dos EUA; 10,4 da Inglaterra; 25\% da Alemanha. Nas importações também a Alemanha cresceu no período de 1932 - 1938, de 8,8\% para $19,1 \% .{ }^{16}$ Importante pontuar que nos anos de guerra esta relação já vinha minguando graças aos bloqueios e indisponibilidade de comércio com a Alemanha devido ao conflito.

\footnotetext{
${ }^{12}$ MOURA, Gerson de. Autonomia na dependência: a política externa brasileira de 1935 a 1942. RJ: Nova Fronteira, 1980 apud GOMES, Ângela de Castro Gomes. A invenção do trabalhismo. Op.cit., p. 183.

${ }^{13}$ LEOPOLDI, M. A. P.; Estratégias de ação empresarial em conjunturas de mudança política. In: Dulce Pandolfi. (Org.). Repensando o Estado Novo. 1ed. Rio de Janeiro: Editora da Fundação Getúlio Vargas, 1999, v. 1. p. 123.

${ }^{14}$ GOMES, Ângela de Castro Gomes. A invenção do trabalhismo. Op.cit. p. 183.

${ }^{15}$ CYTRYNOWICZ, Roney. Guerra sem guerra:...op.cit., p. 33.

${ }^{16}$ HERING, Maria Luiza Renaux. Colonização e indústria no Vale do Itajaí: o modelo catarinense de desenvolvimento. Blumenau: Ed. da FURB, 1987. p. 213.
} 
Neste contexto de trocas, o próprio envio de tropas brasileiras para a Itália, a Força Expedicionária Brasileira - FEB em 1944, representou negociação, apesar da relutância dos Estados Unidos em aceitar esta participação. O historiador Roney Cytrynowicz defende que o envio destas tropas foi muito mais uma necessidade interna à política brasileira, com intuito de fortalecer a base de apoio ao Estado Novo e as Forças Armadas reestruturando-a e reequipando-a - além de projetar o país nas discussões do pós-guerra; do que necessariamente uma decisão ideológica ou política do país na luta internacional contra os totalitarismos europeus, conforme colocado pelo discurso oficial. ${ }^{17}$

Este momento de entrada no conflito mundial marca também importantes transformações administrativas do Estado Novo, como a intensificação da relação estatal com os interesses empresariais do país, representados pela ascensão aos Ministérios do Trabalho, Indústria e Comércio; em conjunto ao Ministério da Justiça (as duas pastas mais importantes do governo); do advogado paulista, especialista em direito comercial e representante do setor industrial, Alexandre Marcondes Filho, ainda em 29 de dezembro de $1941 .{ }^{18}$ O Ministério do Trabalho era o responsável por criar regulamentos sobre as atividades na indústria e no comércio, emergindo uma cidadania regulada pelo Estado, que incorporava as classes trabalhadores na ordem através das leis trabalhistas e dos sindicatos, enquanto os empresários eram convocados a se organizarem em associações de classe de caráter corporativo, afim de efetivar a união entre os interesses empresariais do país e o projeto de governo em voga. ${ }^{19}$

Esta nomeação, aliada a uma forte campanha publicitária e institucional, representou uma intensificação dentro da política nacional de procedimentos de caráter mais mobilizadores da população; além de um anúncio da necessidade de enfrentar a questão da democracia liberal ou mesmo do comunismo, tendo em vista a aliança com os Estados Unidos e a União Soviética, contra o nazi-fascismo. Assim, era importante garantir o controle estatal sobre o vindouro e inevitável processo de "saída" do próprio autoritarismo. ${ }^{20}$

Porém, Ângela de Castro Gomes argumenta que este fato não se identifica como um sinal do início da derrocada do Estado Novo; mas que a tomada de posição e entrada do país na guerra, representa um rearranjo de

\footnotetext{
${ }^{17}$ CYTRYNOWICZ, Roney. Guerra sem guerra:...op.cit., p. 34 - 35.

${ }^{18}$ GOMES, Ângela de Castro Gomes. A invenção do trabalhismo. Op.cit., p. 184.

${ }^{19}$ LEOPOLDI, M. A. P.; Estratégias de ação empresarial em conjunturas de mudança política. In: Dulce Pandolfi. (Org.). Repensando o Estado Novo...op.cit., p. 117.

${ }^{20}$ GOMES, Ângela de Castro Gomes. A invenção do trabalhismo. Op.cit., p. 184 - 185.
} 
forças internas, onde a imagem que se procurava afirmar era de um país forte e unido, mobilizado para sua efetiva construção como futura potência internacional. Assim, a presença do Brasil ao lado dos países aliados pretendia promover esta autoimagem de grandeza. Em contraposição, o inimigo externo justificava todos os sacrifícios e superação que se mostravam acima de embates considerados secundários, ou seja, todas as outras questões sociais. O esforço de guerra, e a intensa mobilização a ele vinculada, eram entendidos como a batalha para o desenvolvimento e defesa do país, que no discurso oficial estava sob uma intensa ameaça. ${ }^{21}$

No esforço de mobilização, é acionado com mais força $o$ Departamento de Imprensa e Propaganda (DIP), ${ }^{22}$ criado com o Decreto-lei n. 1.915 , de 27 de dezembro de 1939, diretamente vinculado ao gabinete presidencial e organizado, nos Estados, como Departamento Estadual de Imprensa e Propaganda (DEIP). Segundo Marlene de Fáveri,

Sua função básica era fiscalizar a imprensa em todo o território nacional, aplicar a censura às mensagens contrárias ao regime, promover a figura de Vargas e divulgar o noticiário oficial, supervisionando os meios de comunicação de massa, e, para tanto foi dividido em cinco seções: radiodifusão, propaganda, cinema e teatro, turismo e imprensa. ${ }^{23}$

Através deste Departamento, fiscalizava-se a imprensa em todo o território nacional, concomitante a promoção da imagem de Vargas, conduzindo a propaganda ideológica para obter base de apoio para a unidade nacional e centralização política. ${ }^{24}$

Nos anos de 1930 e 1940, o trabalho retinha a ideia de virtude imbuída do liberalismo; ser cidadão era produzir riquezas, possuir carteira de trabalho e estar moralmente dentro da concepção dos direitos e deveres para com o Estado, numa relação contratual entre o presidente e o povo, que devia segui-lo, já que dele emanava a doação dos benefícios sociais (restritos ao trabalhador urbano). ${ }^{25}$ Os trabalhadores também passaram a ter o direito a férias remuneradas e jornada de trabalho não superior a oito

${ }^{21}$ GOMES, Ângela de Castro Gomes. A invenção do trabalhismo. Op.cit., p. 186.

${ }^{22}$ A Delegacia de Ordem Política e Social coube fiscalizar e controlar tudo o que saía na imprensa e nas rádios. Cf. CANCELLI, Elizabeth. O mundo da violência: a polícia na era Vargas. 2. ed. Brasília: Editora Universidade de Brasília, 1994. p. 116 - 117.

${ }^{23}$ FÁVERI, Marlene de. Memórias de uma (outra) guerra:...op.cit., p. 349.

${ }^{24}$ GOULART, Silvana. Sob a verdade oficial: ideologia, propaganda e censura no Estado Novo. São Paulo: Marco Zero; CNPQ, 1990.

${ }^{25}$ FÁVERI, Marlene de. Memórias de uma (outra) guerra:...op.cit., p. 301. 
horas, entre outros. Estes direitos não eram entendidos como uma conquista ou reparação aos movimentos sociais, mas sim como obra da generosidade da figura que vinha sendo construída de Vargas como "pai dos pobres. Dentro desta lógica, receber benefícios é um direito, mas também um dever. 26

Instituída pelo Decreto-lei $\mathrm{n}^{\circ} 5.452$, de 1 de maio de 1943, Dia do Trabalho, a Consolidação das Leis Trabalhistas - CLT; reuniu, e ordenou as leis trabalhistas existentes até então. Noto que a data inicial de vigência do novo código coincidirá com o aniversário do Estado Novo, em 10 de novembro do mesmo ano, ocorrência costumeira do período, de criação de datas festivas do regime associadas a concessão de benefícios sociais. ${ }^{27} \mathrm{Com}$ isto, almejava-se submissão, adesão e mobilização, expediente possível através de procedimentos mais participativos e representativos.

A questão sindical é uma chave importante para entender a mobilização e a representação possível de amplas camadas sociais durante o Estado Novo. O modelo sindical implementado por Vargas, articulado ao projeto autoritário, tinha no aliciamento e controle das classes trabalhadoras um objetivo primário. Assim, a organização de "empregados e empregadores" se fazia numa lógica binária: a existência de somente um sindicato por categoria profissional e o caráter eminentemente "público" do sindicato, sob o controle que o Estado.

Era importante aumentar a adesão ao sindicato; e, a forma encontrada pelos ideólogos e arquitetos do regime foi a criação do imposto sindical, a fim de dotar os sindicatos, as federações e as confederações de fartos recursos orçamentários. ${ }^{28}$ Muito mais do que sua manutenção e funcionamento, estes recursos tinham por objetivo atrair cada vez mais associados buscando os serviços essenciais como assistência jurídica e de lazer, inexistentes no Estado. Quanto a questão de quem seria efetivamente tributado, a decisão governamental foi de que todos, filiados ou não a um sindicato, deviam pagar. Conforme decreto $\mathrm{n}^{\circ} 2.377$, de julho de 1940, que obriga todo trabalhador a pagar, compulsoriamente, o correspondente a um dia de trabalho ao sindicato de sua categoria, assegurando-se a este uma receita estável. ${ }^{29}$

${ }^{26}$ GOMES, Ângela de Castro Gomes. A invenção do trabalhismo. Op.cit., p. 181.

${ }^{27}$ GOMES, Angela de Castro. Ministério do Trabalho: uma história vivida e contada. 1. ed. Rio de Janeiro: CPDOC, 2007, v. 1. 3. p. 48.

${ }^{28}$ GOMES, Angela de Castro. Imposto sindical sobrevive há setenta anos. 1 jun. 2008 Disponível em: http://www.revistadehistoria.com.br/secao/artigos/angela-de-castro-gomes-1.

${ }^{29}$ GOMES, Angela de Castro. Ministério do Trabalho:...op.cit., p. 46. 
Quanto a propaganda política, esta se efetivava através do controle direto sobre publicações de revistas e jornais oficiais pelo DIP (exemplo é o jornal A Manhã), mas principalmente por meio de comunicação que mais se expandia na época, o rádio. Através da Rádio Nacional, eram produzidos os programas "Hora do Brasil", e "Crônicas de Interesse Nacional", todos realizados diretamente sob a responsabilidade do DIP. O próprio ministro Marcondes Filho, ocupava os microfones da "Hora do Brasil" todas as quintas-feiras, de janeiro de 1942 a julho de 1945, justamente nos anos do escalar do conflito (discursos que também eram transcritos no editorial do jornal A Manhã no dia seguinte). ${ }^{30}$ Estes programas tinham por objetivo traduzir as ideias centrais do projeto político do Estado Novo, sendo claro e didático, objetivando marcar o ouvinte, usando da repetição e da comunicação direta/emocional, abarcando a divulgação da legislação social, a fim de criar adesão e mobilização a este projeto. ${ }^{31}$ Isto ocorre também através das falas do ministro acerca da campanha de sindicalização, dos programas de construção de vilas operárias e de recreação dos trabalhadores. ${ }^{32}$

O alcance desta campanha se fazia no calor do momento de um estado de guerra, cujos discursos oficiais apregoavam a necessidade de forte mobilização para salvaguardar a integridade e o desenvolvimento nacional, inclusive legitimando a suspensão de direitos trabalhistas anteriormente conquistados e celebrados, ${ }^{33}$ muito mais por pressão de setores industriais (notadamente o têxtil), do que a necessidade de "salvação nacional" no dado momento. ${ }^{34}$

O que acabou por levar o trabalhador a ser encarado como um "soldado da produção", sendo convocado para a "batalha da produção". A propaganda ministerial apontava para um tempo de sacrifícios e de disciplina, onde a resistência ou a tentativa de se aproveitar da situação (para lucro pessoal) seriam encarados como crime de traição. ${ }^{35}$ Este caráter do trabalho ser entendido como uma "batalha", legitimava uma necessidade

\footnotetext{
${ }^{30}$ GOMES, Ângela de Castro Gomes. A invenção do trabalhismo. Op.cit., p. 211.

${ }^{31}$ Ibidem, p. 226.

${ }^{32}$ GOMES, Angela de Castro. Ministério do Trabalho:...op.cit., p. 46.

${ }^{33}$ Por exemplo, em agosto de 1942, governo decretou a restauração da jornada de dez horas, com o argumento de "estado de guerra"; em outubro um decreto suspendia direito de férias em indústrias consideradas essenciais â segurança nacional. Em dezembro era impedida a mobilidade dos trabalhadores nestas mesmas indústrias, transformando o empregado em "desertor" em caso de falta ou desistência do trabalho, conforme decretos n 4.639 (08/1942), n 4.869 (10/1942), n 4.932 (11/1942). Cf. PAOLI, 1987. p. 46 apud GOMES, Ângela de Castro Gomes. A invenção do trabalhismo. Op.cit., p. 225.

${ }^{34}$ Ibidem, p. 225.

35 Ibidem, p. 224.
} 
de ritmo acelerado das atividades num estado de exceção da norma, devido ao esforço de guerra.

Também era imputado pelo discurso propagandístico, o papel do trabalhador como vigilantes da ordem, sendo prática bem vista a delação de sujeitos vistos como resistentes a adesão obrigatória ao regime. ${ }^{36} \mathrm{O}$ que abria a possibilidade, recorrente na época, de resolver conflitos pessoais através de denúncias, muitas vezes sem fundamentos, de supostos crimes, que revestiam o objetivo de vingar-se ou tirar proveito de desafetos. Entendia-se o inimigo a ser combatido, não apenas como os subversivos, representado pelo sujeito ligado aos interesses não nacionais, um inimigo externo infiltrado; mas também, e mais notadamente neste discurso, o inimigo interno, inimigo este no campo do trabalho, identificado como o "malandro", ou o escamoteador de preços (tema desenvolvido posteriormente neste texto).

Esta situação foi instituída oficialmente através do decreto-lei 6.688 de 13 de julho de 1944, que suspendeu vários dos recém adquiridos direitos trabalhistas. O que significou a implantação da citada "batalha da produção", no caso específico de São Paulo, voltada à indústria têxtil, setor mais dinâmico da indústria daquela cidade, o qual sofreu intervenção militar direta graças ao decreto. O papel dos "soldados do trabalho" e dos "sindicatos-quartéis" nesta "batalha" que ocorreria nas fábricas era o de produzir, independentemente de normas ou regulamentos trabalhistas, pois o momento era de exceção e perigo para a nação. ${ }^{37}$

Para os grupos urbanos como os operários, população pobre e imigrantes, esta mobilização não significou um "simples" alinhamento, mas sim uma intervenção em seus cotidianos, instituindo um regime de mobilização estritamente militar, que atendia a interesses do Estado Novo e de grupos como a indústria têxtil e os setores exportadores. Com isto, principalmente os trabalhadores têxteis, foram tratados como soldados e mobilizados para uma guerra - a do front interno, longe dos campos de batalha europeus, mas que apresentava também uma situação de exceção da normalidade. As unidades industriais transformaram-se em fábricas militarizadas; e toda gama de imigrantes passaram a ser vistos como inimigos da nação. ${ }^{38} \mathrm{O}$ objetivo era supostamente garantir a produção e o abastecimento do mercado interno, inclusive mantendo os preços baixos para os "tecidos populares". Porém, isto ocorreu muito mais pela pressão patronal mencionada, e com o objetivo de baratear e precarizar o trabalho e

\footnotetext{
${ }^{36}$ Ibidem, p. 225.

${ }^{37}$ GOMES, Angela de Castro. Ministério do Trabalho:...op.cit., p. 48.

${ }^{38}$ CYTRYNOWICZ, Roney. Guerra sem guerra:...op.cit., p. 19 - 20.
} 
os produtos, levando a lucros superiores aos empresários, os quais foram apontados nos decorrentes anos de conflito, gerados também pela situação do mercado internacional e pelo desabastecimento do mercado interno. ${ }^{39}$

Quanto aos setores das elites e as classes médias, estes não foram atingidos igualmente pela mobilização; atingiu primordialmente o campo do trabalho da população urbana pobre, mas jamais normatizou efetivamente a ação, muitas vezes especulativa, de industriais e comerciantes (principalmente grandes atacadistas). A Segunda Guerra Mundial foi um período de oportunidades de enormes lucros, através de intensa especulação imobiliária, financeira, de preços e de estoques; na agricultura, pecuária, nos transportes; sem um controle efetivo do governo. Fato confirmado pelos próprios relatórios internos da Coordenação de Mobilização Econômica, criada para coordenar a economia de guerra, que reconhecem a ineficiência deste órgão neste intento. ${ }^{40}$

A Coordenação de Mobilização Econômica foi criada pelo governo federal, em 28 de setembro de 1942, amparado pelo decreto-lei n 10.358 de 31 de agosto do mesmo ano, em conjunto ao seu anexo decreto-lei n. 4.750 de 28 de setembro; que havia declarado o estado beligerante. Seu papel era de centralizar e controlar a economia durante esses anos, conforme artigo primeiro: "Ficam mobilizados, a serviço do Brasil, todas as utilidades e recursos econômicos existentes no território nacional, seja qual for a sua origem, caráter, propriedade ou vínculo". ${ }^{41} \mathrm{O}$ próprio papel do órgão estava dentro da lógica de barganha mencionada, que era: atuar em variados setores da produção industrial nacional, dos quais muitos de interesse ao esforço de guerra estadunidense, que por sua vez garantiam a compra desta produção por preços recorrentemente acima do mercado. ${ }^{42}$

Cytrynowicz argumenta que a escassez que atingiu as classes médias e altas em São Paulo, e presumivelmente nas outras cidades brasileiras, foi muito mais um álibi para instituir um clima de privações de forma a tornar a guerra um experiência coletiva, a qual devia unir todos os brasileiros, independente de distinções sociais. Objetivava efetivar o projeto estado-novista através de pretensa "homogeneização" da sociedade sob seus parâmetros. A escassez de produtos, combustível, pão, leite, era muito mais uma variável interna às questões urbanas da cidade do que um impacto real

\footnotetext{
${ }^{39}$ Ibidem, p. 29 - 30.

40 Ibidem, p. 30.

41 Decreto-lei N. 4.750 de 28 de Setembro de 1942. Disponível em: http://legis.senado.gov.br/legislacao/ListaPublicacoes.action?id=25590

${ }^{42}$ CYTRYNOWICZ, Roney. Guerra sem guerra:...op.cit., p. 246.
} 
e objetivo advinda do conflito. ${ }^{43}$ Assim, eram dirigidos estes efeitos de mobilização as classes médias e elites a fim de incluir estes setores ao ideário político do Estado Novo, enquanto aos trabalhadores urbanos era direcionada uma intervenção militar direta. ${ }^{44}$

Não existiu, conforme percebeu Cytrynowicz na cidade de São Paulo, qualquer percepção, por parte da população, de uma real ameaça pelo estado de guerra. Iniciativas governamentais ocorreram, como: o "pão de guerra" (pão integral), lançado em 1942 na primeira reunião da Coordenação de Mobilização Econômica; a "Campanha de vitaminas para o Povo", da "Horta da Vitória" (hortas que deveriam ser plantadas nos quintais das residências), campanha do leite, do sapato, a produção de gasogênio ${ }^{45}$ para ônibus e carros privados; o que acabou por produzir efetivamente um efeito de mobilização. Houve também as dificuldades de importação, mas elas nunca definiram a escassez ou a privação real, como ocorrido nos teatros de guerra da Europa e do Pacífico. ${ }^{46}$

Como foi possível então, manter esta mobilização apesar da inexistência de motivos concretos para tanto? Uma resposta é a própria magnitude da guerra, atestada diariamente pelas manchetes de jornais, programas radiofônicos e afins, que pareciam confirmar a suposta urgência e objetividade da escassez. A especulação alimentava a cena da guerra interna, mas sem nunca passar de um álibi; desta forma, o conflito nunca serviu de fator explicativo objetivo da escassez. Guerra e escassez são associações recorrentes; no caso brasileiro, nota-se uma junção de guerra e especulação, que significou toda sorte de falta de produtos, preços inflacionados e pequenos golpes contra os consumidores. Com isto, a especulação de preços acaba por tornar-se categoria naturalizada de uma suposta economia de guerra, o que obscurece as reais motivações por traz da concreta escassez. ${ }^{47}$

Na medida em que se mobiliza a população para o front interno, o discurso em voga acentua a questão nacional preponderante - a alimentação e a saúde da população, e a escassez relativa se torna alarme, produzida por esta mobilização. Durante o período do conflito, a situação alimentar da

\footnotetext{
${ }^{43}$ Ibidem, p. 24 - 25.

44 Ibidem, p. 27.

45 Gasogênio: gás de síntese, uma mistura combustível de gases, produzida a partir da combustão incompleta de combustíveis sólidos. No Brasil, durante a guerra, existiu racionamento de petróleo. Uma das únicas opções para veículos particulares era o uso deste gás. Uso este incentivado, e em grande parte patrocinado, pelo governo. Cf. FÁVERI, Marlene de. Memórias de uma (outra) guerra:...op.cit., p. 385-386.

${ }^{46}$ CYTRYNOWICZ, Roney. Guerra sem guerra:...op.cit., p. 24.

${ }^{47}$ Ibidem, p. 232.
} 
população brasileira não piorou; mas o alarde sobre esta serviu para que comerciantes aproveitarem-se da situação e aumentarem seus lucros. Mesmo com a indicação de que supostamente a economia nacional deveria estar sendo controlada pela Coordenação de Mobilização Econômica, o setor que realmente foi mobilizado no país foi o do trabalho, ou seja, a economia não sofreu esta mesma intervenção. ${ }^{48}$

O que a guerra na Europa efetivamente produziu foi a escassez de importações, conjuntamente a diversificação e aumento das exportações das indústrias nacionais. Assim, houve um crescimento da produção interna voltada ao mercado externo; o índice de preços de exportação cresceu $75 \%$ entre 1937 e 1942, com um câmbio que decresceu 25\%, esta última, medida governamental implantada durante a década de 1930, tinha por objetivo desestimula as importações de manufaturados impulsionando assim a indústria nacional. ${ }^{49} \mathrm{Com}$ isto, ocorreu um aumento dos lucros com as exportações na casa de $45 \%$ no período, de acordo com Celso Furtado. ${ }^{50}$ Isto promoveu uma escassez da oferta interna de produtos, produzida pelo crescimento das exportações; que geraram ótimos negócios e lucros aos exportadores. Além de uma diversificação dos produtos exportados, que além da indústria têxtil citada, englobava cacau, algodão e minerais. ${ }^{51}$

Nota-se que a escassez e alta inflacionária foram ações dos especuladores, os valendo-se do estado de guerra, criaram cenários especulativos para seus ganhos pessoais. Segundo Cytrynowicz, no Estado de São Paulo, houve forte aumento de produção de açúcar, algodão, óleos vegetais, lã e carne, graças também a incentivos governamentais; justamente no momento de maior alarde sobre a suposta escassez de gêneros de primeira necessidade. ${ }^{52}$

Existiam medidas do Tribunal de Segurança Nacional, criado em 1936 e estendido para o período,$^{53}$ a fim de instituir penas para comerciantes

${ }^{48}$ CYTRYNOWICZ, Roney. Guerra sem guerra:...op.cit., p. 233.

${ }^{49}$ Entre os anos de 1929 e 1939, a taxa de câmbio sofre uma desvalorização de 109\% em virtude da queda das exportações e dos encargos da dívida externa. Cf. LEOPOLDI, M. A. P.; Estratégias de ação empresarial em conjunturas de mudança política. In: Dulce Pandolfi. (Org.). Repensando o Estado Novo...op.cit., p. 122.

${ }^{50}$ FURTADO, Celso. Formação econômica do Brasil. 19. ed. São Paulo: Ed. Nacional, 1984. p. $206-207$.

${ }^{51}$ LEOPOLDI, M. A. P.; Estratégias de ação empresarial em conjunturas de mudança política. In: Dulce Pandolfi. (Org.). Repensando o Estado Novo...op.cit., p. 123.

${ }^{52}$ CYTRYNOWICZ, Roney. Guerra sem guerra:...op.cit., p. 233 - 234.

53 Órgão Estatal central que ficava na cidade do Rio de Janeiro, capital federal. Este foi instituído pela lei n. 244, de 11 de setembro de 1936, entendido como um tribunal de exceção a fim de defender os interesses do Estado e enquadrar os "criminosos" do levante da Intentona Comunista (1935). Que apesar de seu caráter temporário, sobreviveu até ao fim do 
que retivessem mercadorias em estoques, provocassem altas e baixas artificiais dos preços ou fraudassem pesos e qualidades dos produtos. Porém, estas medidas não garantiram, nem ao menos coibiram as práticas citadas, que geralmente eram justificadas pela dificuldade de aquisição de determinadas matérias-primas, encarecimento dos transportes e das taxas de seguro. Isto, num cenário onde o governo federal, desde a segunda semana de da guerra na Europa, ainda em setembro de 1939; havia tabelado os preços dos gêneros alimentícios de primeira necessidade. ${ }^{54}$

No fim do ano de 1944, o governo, frente o descontrole dos preços, havia instituído que, além de perder as licenças, os especuladores teriam suas fotos e de seus estabelecimentos publicadas nos jornais da capital do Estado de São Paulo, e processados no Tribunal de Segurança Nacional. ${ }^{55}$ Todas medidas que não surtiram efeito frente a prática recorrente de açambarcamento de preços.

Este cenário de certa 'complacência' das autoridades aos abusos dos comerciantes e industriais, pode ser explicado, principalmente, nos anos finais de guerra, graças a uma tentativa deliberada de Vargas em aliciar o setor industrial, notadamente paulista, que na perspectiva do fim do conflito e de posteriores eleições tenderiam a unir-se aos grupos de oposição. Neste contexto, o governante visita repetidamente São Paulo e promove vários congressos de economia, preocupados com a organização industrial do país. ${ }^{56} \mathrm{O}$ Estado Novo também organizou duas agências que incidiam em diferentes ministérios para planejar os rumos da economia brasileira: a Comissão de Planejamento Econômico e a Comissão de Política Industrial e Comercial - ainda em 1945. ${ }^{57}$ Porém, esta associação entre industriais e o governo se mostrou fraca, pois não assegurou a manutenção do regime ou a eleição de Vargas em 1945.

Ainda assim, esta aproximação com os industriais, classes médias e operariado urbano representava um novo pacto social para o país, pois retirava a exclusividade tradicional de representação das elites agrárias. Representando com isto uma transição da economia agroexportadora para uma economia industrial vinculada ao liberalismo. A industrialização brasileira foi estimulada, desde a década de 1930, pelas políticas do Estado,

regime, 1945, enquadrando toda sorte de "crimes" contra a segurança nacional. Cf. FÁVERI, Marlene de. Memórias de uma (outra) guerra:...op.cit., p. 97 - 98.

${ }^{54}$ CYTRYNOWICZ, Roney. Guerra sem guerra:...op.cit., p. 235.

${ }^{55}$ Ibidem, p. 246.

${ }^{56}$ CYTRYNOWICZ, Roney. Guerra sem guerra:...op.cit., p. 239.

${ }^{57}$ LEOPOLDI, M. A. P.; Estratégias de ação empresarial em conjunturas de mudança política. In: Dulce Pandolfi. (Org.). Repensando o Estado Novo...op.cit., p. 116 - 117. 
pela economia do café e pelo mercado de serviços urbanos, economia esta mais diversificada de substituição de importações. ${ }^{58}$

Paradoxalmente, o ideário liberal vinculado a esta modernização, foi esvaziado pelo autoritarismo do Estado Novo. A escalada da intervenção do Estado na economia já vinha emergindo desde a República Velha, com as sucessivas crises do preço do café; e só acentuou-se com a acessão de Vargas que, com o regime do Estado Novo, marcou a hegemonia estatal sob a sociedade. Apontamento que vem de encontro à tradição brasileira de instituições liberais, funcionando autoritariamente, de uma hibridez que combina práticas autoritárias e liberais ao mesmo tempo, pontuadas por períodos de predominância de um ou de outra, mas nunca desaparecendo completamente esta dualidade. ${ }^{59}$

A campanha de mobilização visava um violento enquadramento segundo os ideais de ordem estadonovista. Os anos de 1937 - 1945 significaram a inclusão controlada e a mobilização negociada de setores das classes médias e altas e a violenta intervenção e mobilização militar sobre a população pobre, operários e imigrantes. ${ }^{60} \mathrm{O}$ objetivo de todo este processo político/propagandístico, capitaneado pelos programas radiofônicos do ministro Marcondes Filho desde 1942, era o de garantir uma transição satisfatória para as elites, com o fim eminente do Estado Novo. ${ }^{61}$ Isto se efetivou na Constituinte de 1946, com o sucesso da ideia de nação entendida como sociedade conciliadora; e, as práticas autoritárias já citadas se mantiveram nas instituições agora democráticas, também com a manutenção do estado corporativista, o qual foi o canal para a inclusão das classes médias e altas aos canais de poder.

Uma das políticas adotada durante o regime Vargas, foi a implementação de um sistema corporativo para o país, uma relação de mão dupla entre o Estado e a entidade de classe, com o intuito de aproximação e coesão do crescente setor empresarial. Antes de 1931, todas as iniciativas de formação de entidades representativas dos industriais teve um caráter privado, concentrados no eixo Rio-São Paulo e ligadas no geral ao setor têxtil, com um discurso de defenda de uma política de Estado eminentemente protecionista. Uma nova fase é inaugurada com a revolução de 1930, onde as iniciativas privadas organizativas dos industriais são

\footnotetext{
${ }^{58}$ Ibidem, p. 126.

59 TRINDADE, Hélgio. Bases da democracia brasileira: lógica liberal e práxis autoritária, 1822-1945. In Alain Rouquié et al.,(org.). Como Renascem as Democracias. Ed. Brasiliense, São Paulo, 1986. p. 52.

${ }^{60}$ CYTRYNOWICZ, Roney. Guerra sem guerra:...op.cit., p. 35.

${ }^{61}$ GOMES, Ângela de Castro Gomes. A invenção do trabalhismo. Op.cit., p. 261.
} 
suplantadas em varias áreas empresariais, pela implementação do sistema corporativo, abarcando também os trabalhadores da indústria e do comércio. As entidades organizadas no período,

Tendem a assumir um caráter de entidades exclusivas (são o único canal de relação entre indústria e Estado), organizadas numa estrutura piramidal e hierárquica, com uma única organização de cúpula, a Confederação Nacional da Indústria (formada em 1938), uma organização regional eclética por Estado (federação) e sindicatos locais (apenas um por categoria). Nos anos 30 e 40, as federações se formam nas regiões industrializadas, onde já existiam associações de caráter privado: Rio de Janeiro, São Paulo, Minas e Rio Grande do Sul. Posteriormente as federações vão-se constituir em todos os Estados brasileiros, gerando um "pacto federativo". ${ }^{62}$

Os discursos destas entidades permanecem com o caráter protecionista, onde o Estado tem por objetivo ser a mola propulsora do desenvolvimento industrial. Estes empresários, e suas entidades de representação, estabelecem uma aliança com o projeto modernizador do regime, onde o corporativismo é o canal através do qual ela se efetiva. $\mathrm{O}$ corporativismo, assim, representa uma forma efetiva de interação entre indústria e governo, a adesão a este modelo, com a formação de entidades representativas dos empresários junto ao Ministério do Trabalho; abriu o acesso destes, e inicialmente apenas a eles, os primeiros a se adequarem ao novo sistema:

Às agências decisórias nas áreas de política industrial, legislação trabalhista e sindical, comércio exterior e política tributária. A representação corporativa dos industriais viabilizou assim a sua participação nas políticas fundamentais dos anos 30 e 40, as quais se formulavam nas agências do Executivo. ${ }^{63}$

Esta adaptação que os industriais fizeram de suas associações ao modelo corporativo, sem dúvida contribuiu para consolidar a relação

\footnotetext{
${ }^{62}$ LEOPOLDI, M. A. P.; Estratégias de ação empresarial em conjunturas de mudança política. In: Dulce Pandolfi. (Org.). Repensando o Estado Novo...op.cit., p. 124 - 125.

${ }^{63}$ LEOPOLDI, M. A. P.; Estratégias de ação empresarial em conjunturas de mudança política. In: Dulce Pandolfi. (Org.). Repensando o Estado Novo...op.cit., p. 117.
} 
empresário-Estado que levou o país a crescer puxado pela indústria do Sudeste, inclusive permanecendo até o segundo governo Vargas, já na década de 1950. ${ }^{64}$ Modelo este que começa a sofrer alterações a partir da morte do presidente em 1954, com o aparecimento das associações paralelas da indústria, um modelo híbrido acende, onde as entidades associativas empresariais não mais se submetem ao controle do Ministério do Trabalho, diferentemente do modelo corporativista, representando a emergência de uma nova forma fragmentada de fazer política industrial no Brasil. ${ }^{65}$

Quanto a legislação trabalhista e sindical que foi sendo implantada ao longo da década de 30, culminando na CLT de 1943, permitiu que o crescimento industrial se fizesse sem turbulências sociais. Ao final da década de 1940, já estava em funcionamento um sistema de previdência social para os trabalhadores urbanos, englobando seguro contra acidentes de trabalho, pensões e aposentadorias, política habitacional e assistência hospitalar. $\mathrm{O}$ crescimento industrial foi significativo no período, graças a estas amplas medidas governamentais, "a industrial na década de $30 \mathrm{cresceu}$ $125 \%$. Enquanto no mesmo período, a agricultura cresce "apenas" $20 \% " .66$

Isto representa o referencial nacionalista-desenvolvimentista em voga no regime Vargas, que desde meados de 1930, tinha como referencial orientador das políticas governamentais estes temas, que lançava mão de uma política industrial protecionista, devido a emergência da crise externa que já vinha desde 1929. Nesta lógica é conferido ao Estado o papel de regular a crise e reorganizar a economia, a fim de alcançar um desenvolvimento industrial entendido como objetivo estratégico de governo, o qual envolvia neste ideário, empresários industriais, políticos e intelectuais. ${ }^{67}$

René Rémond afirma que o campo do político, que já não tem fronteiras fixas, é muito ampliado numa situação de guerra. Ele questiona: "Em tempo de guerra, o que não é político?", para logo em seguida responder, "O moral do país, o abastecimento dos exércitos, a divisão da escassez, são tarefas que cabem ao poder público, pois envolvem a salvação da nação.”. ${ }^{68}$ Assim, o campo da política tem por característica, como demonstrado pela historiografia, interferir e ser interferido pelo campo da

\footnotetext{
${ }^{64}$ Ibidem, p. 124.

65 Ibidem, p. 125.

${ }^{66}$ LEOPOLDI, M. A. P.; Estratégias de ação empresarial em conjunturas de mudança política. In: Dulce Pandolfi. (Org.). Repensando o Estado Novo...op.cit., p. 122.

${ }^{67}$ Ibidem, p. 121.

${ }^{68}$ RÉMOND, René. Do Político. In: RÉMOND, René. (Org.) Por uma História Política. Rio de Janeiro: Fundação Getúlio Vargas, 2003. p. 443.
} 
economia. Tendo reflexos sobre todo o corpo social e as relações possíveis dentro deste clima de intensas produções de imaginários sociais.

Recebido em outubro de 2015.

Aprovado em dezembro de 2015. 